\title{
Polychlorinated Naphthalenes in the Global Atmospheric Passive Sampling (GAPS) Study
}

Sum Chi Lee ${ }^{1}$, Tom Harner ${ }^{1} *$, Karla Pozo ${ }^{1}$, Mahiba Shoeib ${ }^{1}$, Frank Wania ${ }^{2}$, Derek C. G. Muir ${ }^{3}$, Leonard A. Barrie ${ }^{4}$ and Kevin C. Jones ${ }^{5}$

${ }^{1}$ Science and Technology Branch, Environment Canada, 4905 Dufferin Street, Toronto, Ontario M3H 5T4, Canada

${ }^{2}$ Department of Physical and Environmental Sciences, University of Toronto at Scarborough, 1265 Military Trail, Toronto, Ontario M1C 1A4, Canada

${ }^{3}$ Water Science and Technology Directorate, Environment Canada, Burlington, Ontario L7R 4A6, Canada

${ }^{4}$ Environment Division, World Meteorological Organization (WMO), Geneva, Switzerland

${ }^{5}$ Centre for Chemicals Management, and Environmental Science Department, Lancaster Environment Centre, Lancaster University, Lancaster LA1 4YQ, United Kingdom

* Corresponding author. Tel.: +1-416-739-4837; Fax: +1-416-739-5708

Email address: Tom.Harner@ec.gc.ca (T. Harner)

\section{Supplementary Information}

\section{Six figures}

Figure S1: $\sum \mathrm{PCN}$ concentrations $\left(\mathrm{pg} / \mathrm{m}^{3}\right)$ in air with GAPS sites classified into categories: i) background, ii) rural, iii) urban, iv) agricultural and v) polar (within the Arctic or Antarctic Circle).

Figures S2-6 summarize the congener profiles (relative contribution of congeners to their respective homologue group) in Halowax 1014 and in air samples from background, rural, urban, agricultural and polar GAPS sites, respectively. The light-colored bars represent the combustionrelated congeners that are relatively enriched or predominant in air and fly ash from combustion processes.

Three tables (see Excel file)

Table S1: $\sum$ PCN air concentrations $\left(\mathrm{pg} / \mathrm{m}^{3}\right)$ between December 2004 and March 2005 at GAPS sites.

Table S2: Comparison of air concentrations $\left(\mathrm{pg} / \mathrm{m}^{3}\right)$ of $\sum \mathrm{PCN}$ in GAPS with results from other studies.

Table S3: Homologue distribution and $\sum \mathrm{PCN}_{\text {combustion }} / \sum \mathrm{PCN}$. 


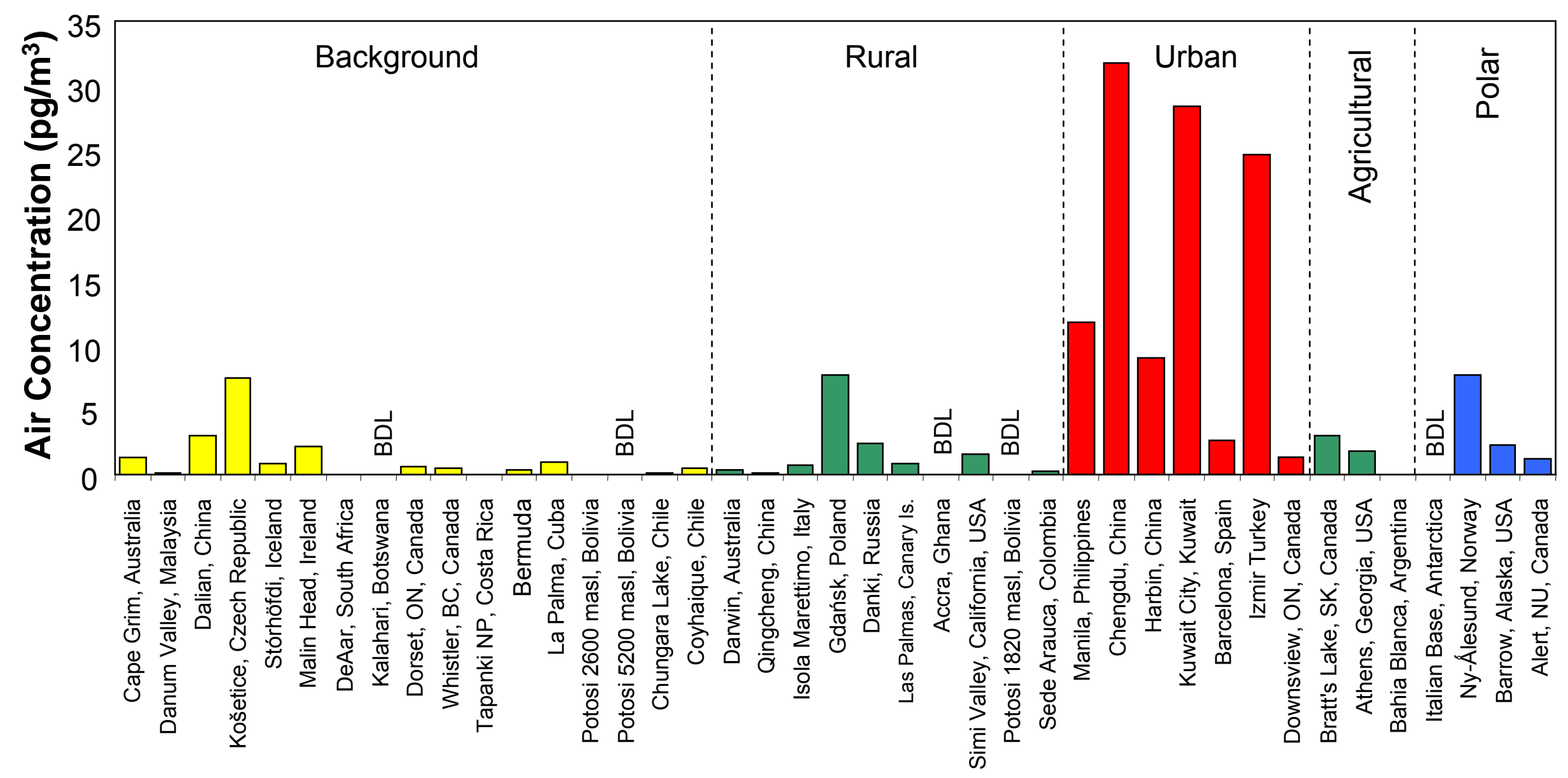

Figure S1. $\Sigma P C N$ concentrations $\left(\mathrm{pg} / \mathrm{m}^{3}\right)$ in air with GAPS sites classified into categories: i) background, ii) rural, iii) urban, iv) agricultural and v) polar (within the Arctic or Antarctic Circle). 

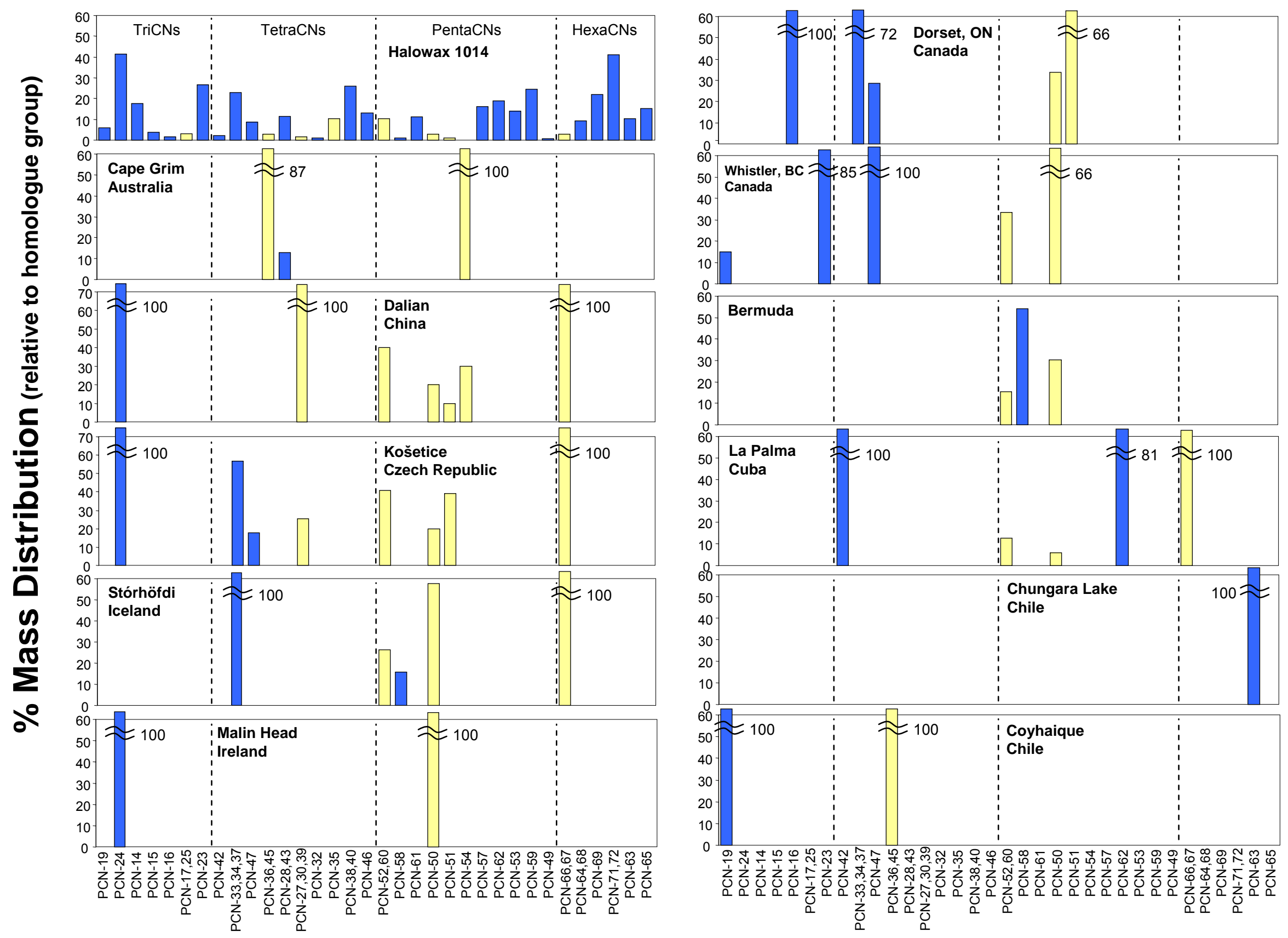

Figure S2. Congener profiles (congeners expressed as relative contribution to their respective homolog group) in air samples from background sites and in Halowax 1014. 


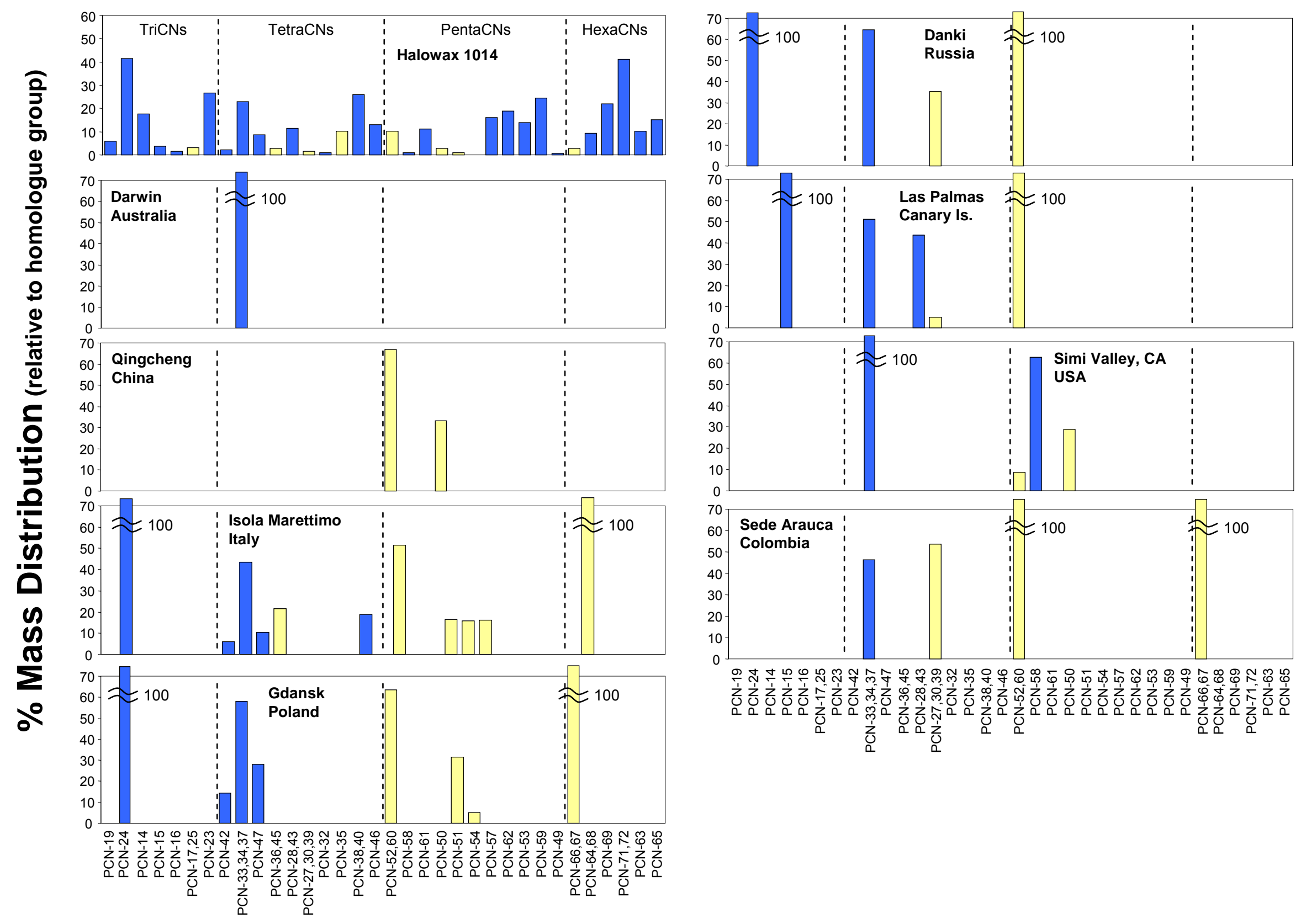

Figure S3. Congener profiles (congeners expressed as relative contribution to their respective homolog group) in air samples from rural sites and in Halowax 1014. 

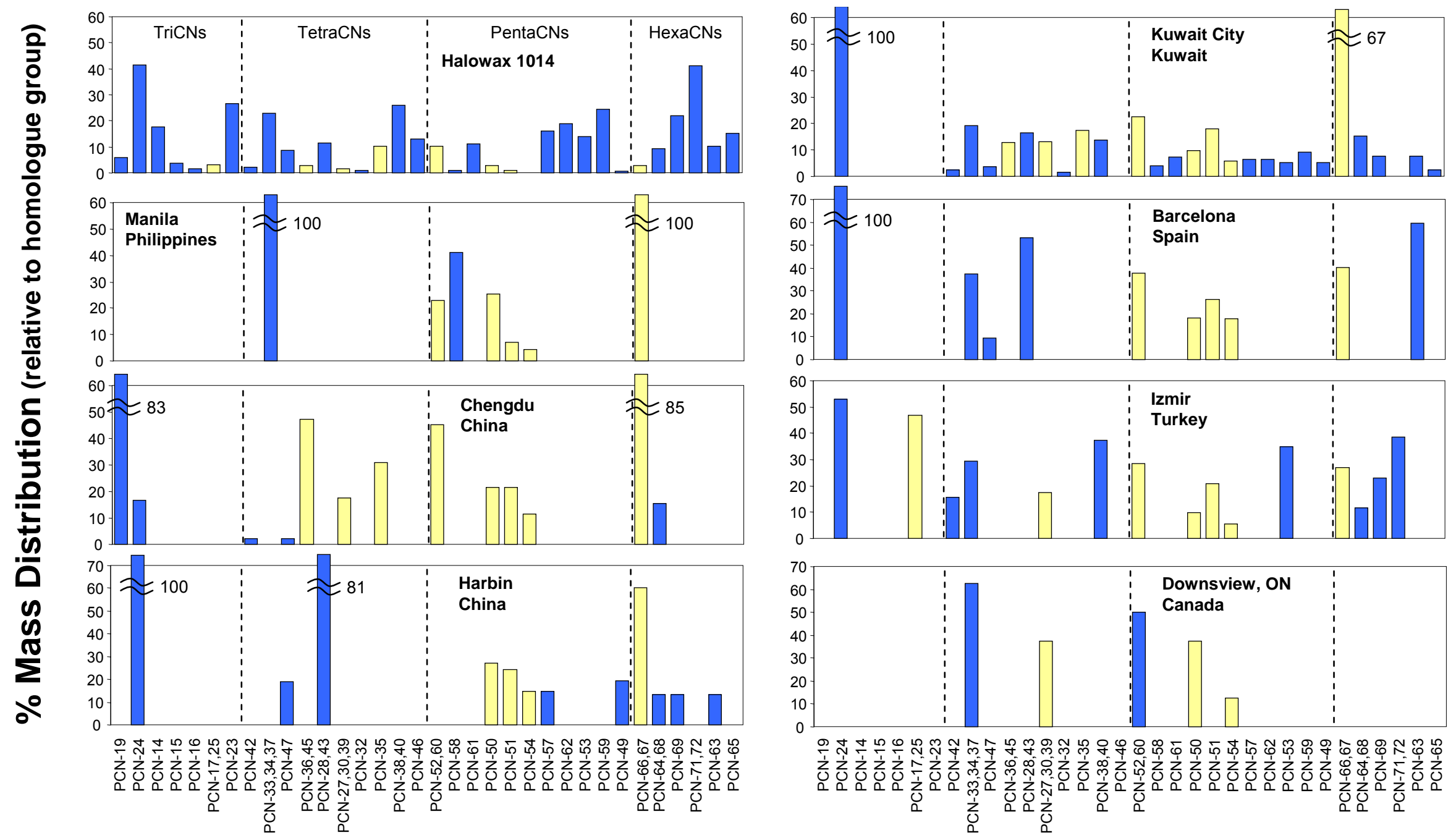

Figure S4. Congener profiles (congeners expressed as relative contribution to their respective homolog group) in air samples from urban sites and in Halowax 1014. 

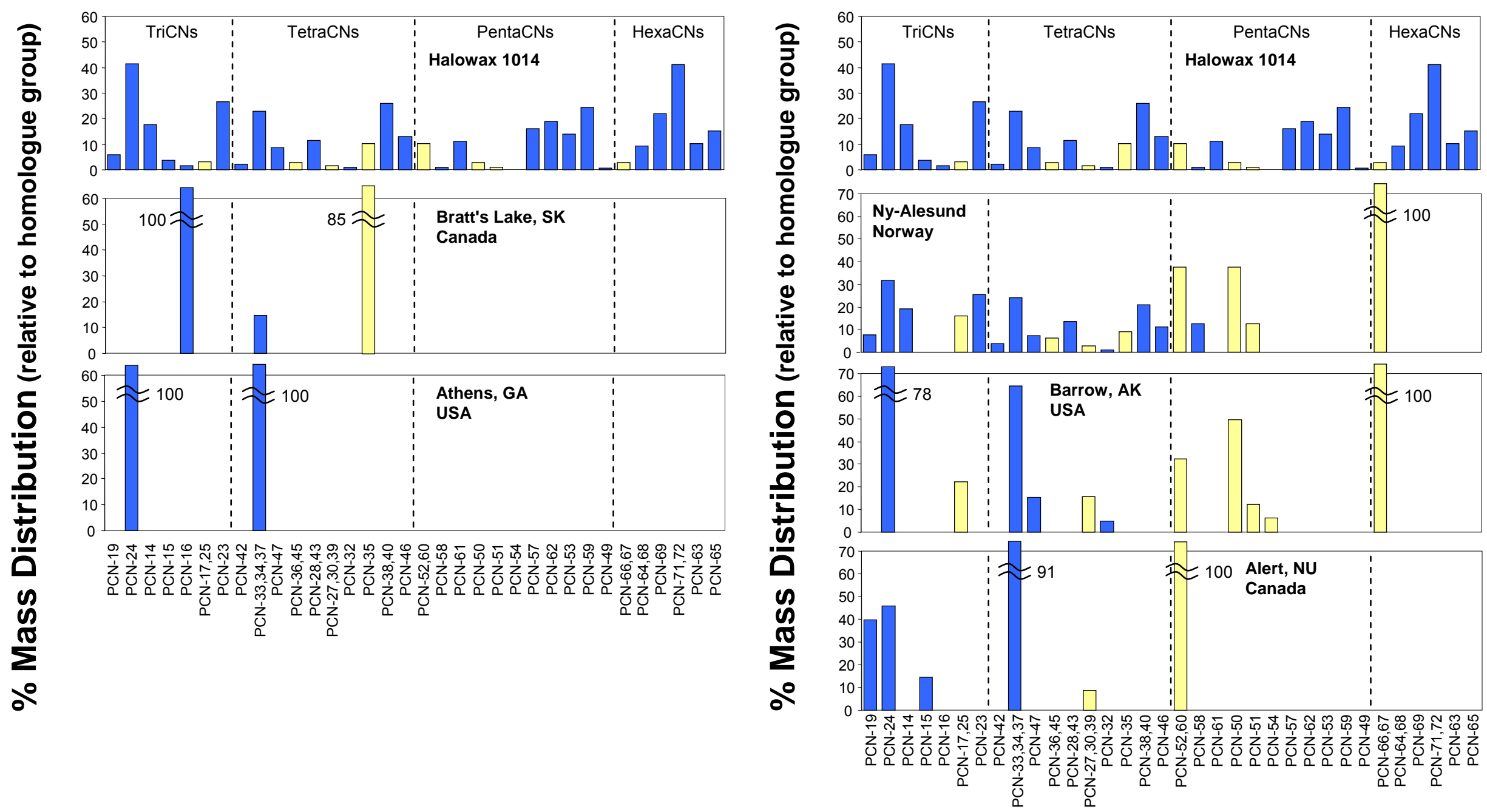

Figure S5. Congener profiles (congeners expressed as relative contribution to their respective homolog group) in air samples from agricultural sites and in Halowax 1014.

Figure S6. Congener profiles (congeners expressed as relative contribution to their respective homolog group) in air samples from Arctic sites and in Halowax 1014. 